\title{
NOS EXTREMOS DO DIREITO (SCHMITT E PACHUKANIS)
}

\author{
ALYSSON LEANDRO MASCARO
}

A literatura jurídica do final do século XX praticamente desconhece outra perspectiva filosófica sobre o fenômeno jurídico que não a institucional-normativista. Kelsen, ao final de um século de intensos debates jusfilosóficos, assenta-se definitivamente, para o jurista mediano, no panteão de maior de todos os pensadores do direito. Sua vitória é, na verdade, a vitória de um amplo espectro de dominação política, econômica e social de molde liberal, que vê nas instituições a salvaguarda das relações sociais e, fundamentalmente, a salvaguarda do capital.

Os debates da teoria do direito resumem-se, nesta perspectiva institucionalista e normativista, a questões incidentais, como o papel do direito internacional e sua correlação com a soberania nacional. O próprio Kelsen, quando revisto pelos liberais, é somente repreendido em pequenos problemas. Bobbio, que tanto encanta o estudante de direito com seu didatismo, pouco deixaria de assinar na obra de Kelsen como se fosse sua. Assim, parece que no plano da teoria jurídica contemporânea nada mais resta a não ser aprofundar o campo único - institucionalista e normativista - de atuação do jurista e do pensador jurídico-político.

No entanto, escondidas nos porões do século, teimam em se levantar as lembranças do pensamento jurídico radical. Duas novas obras brasileiras resgatam esses porões: Marxismo e direito - um estudo sobre Pachukanis, de Márcio Bilharinho Naves (São Paulo, Boitempo, 2000) e Carl Schmitt e a fundamentação do direito, de Ronaldo Porto Macedo Jr. (São Paulo, Max Limonad, 2001). Cada qual trata de um dos dois extremos desta teoria político-jurídica radical: o conservador Carl Schmitt, por muitos considerado (polemicamente) o jurista do nazismo, e o jurista re- 
volucionário Pachukanis, cuja obra é em grande parte um pedaço da história da Revolução Soviética a partir de 1917.

Paradoxalmente em comum, cada qual, em seu extremo, aponta críticas contundentes ao modelo institucionalista-normativista que tanto faz a voga contemporânea. Kelsen, para ambos, talvez seja um modelo a ser refutado. A ironia está nos caminhos com que cada qual, de um lado e de outro, ultrapassa o direito para buscar o cerne da política (e, no caso de Pachukanis, também a economia política). O resgate da política, e de uma teoria política realista, que tanto animou Carl Schmitt, e que tanto ensejou as demolidoras teorias marxistas de Pachukanis, talvez ainda hoje tenham muito a ecoar numa sociedade capitalista mundial na qual sua política utiliza de armas que não podem dizer sejam exatamente jurídicas.

\section{CARL SCHMITT E O DIREITO}

A obra de Ronaldo Porto Macedo Jr. é, originalmente, dissertação de mestrado defendida na USP, no Departamento de Filosofia. Seu enfoque traça uma trilha pouco explorada na compreensão do pensamento de Carl Scmitt, que é o da sua teoria jurídica. Em geral, Schmitt é tomado pelo seu pensamento político ou então, para dentro do mundo jurídico, é considerado pelos seus estudos de direito constitucional. A teoria geral do direito, este campo intermediário entre uma filosofia política e a técnica jurídica em específico, é o tema explorado pela obra de Porto Macedo Jr.

Algumas perspectivas são ressaltadas nesta análise da teoria jurídica de Schmitt, a principal delas a do decisionismo. A teoria do decisionismo, pela abordagem de Schmitt, filia-se a toda uma tradição que se pode perceber desde Hobbes até Donoso Cortés. Para o que diz respeito ao momento especificamente jurídico (ou seja, para a teoria geral do direito), as primeiras obras de Schmitt situam o fenômeno jurídico não na norma e seus comandos imperativos, mas na decisão, fazendo da sentença um elemento de importância muito mais relevante ao direito do que a legislação. Para a teoria política, o decisionismo revelará o encaminhamento realista da organização política européia, que conheceu momentos de neutralização burguesa no século XIX mas que, por meio do nazismo, do fascismo e da União Soviética, viu crescer novamente, em pleno século $\mathrm{XX}$, um pensamento de tipo não liberal.

O decisionismo de Schmitt varia de momentos de total desvinculação a preceitos éticos até a extremos de conservadorismo religioso de 
fundo católico. Trata Porto Macedo Jr. deste pêndulo de Schmitt: "Para o decisionismo schmittiano não há um fundamento metafísico, teológico ou baseado numa moral humanitária, tal como ocorreu nos séculos XVI, XVII e XVIII. Para ele, ao menos nesta fase de seu pensamento (dos anos 1920), não há fundamento para a decisão moral. Neste sentido, pode-se dizer que, nesta fase, Schmitt assume uma posição muito próxima de um relativismo moral de inspiração nietzschiana ou mesmo de um ceticismo moral de molde hobbesiano. Veremos que posteriormente Schmitt admite que as instituições sociais atuam como um "fundamento" ou ao menos como parâmetro para as decisões morais. Ao admiti-lo Schmitt explicita os fundamentos cristãos e conservadores de seu pensamento. Ocorre, todavia, que a sociedade como ponto de referência da decisão moral não atenderá todos os requisitos de um fundamento metafísico imutável. Será ela sempre uma referência cambiante e que se repensa a cada instante. Tal como para Hobbes, para o decisionismo schmittiano não há um fundamento para a autoridade que decide e cria direito. 'Auctoritas non veritas, facit legem'. Para o jurista alemão nem a moral nem o direito têm um fundamento metafísico claro e transparente" (pp. 51 e 52).

Além da perspectiva do decisionismo, outras questões estão a ela intrinsicamente ligadas, como soberania e exceção. A conhecida frase de Schmitt, de que "soberano é quem decide sobre o Estado de exceção", não pode ser compreendida, segundo Porto Macedo Jr., simplesmente como um elogio da ditadura ou da própria exceção. Segundo o autor, Schmitt trama uma rede a partir da qual estes conceitos passam a ser necessariamente referentes um ao outro. Estas conexões, que fazem de Schmitt um pensador extremamente complexo e refinado do direito e da política, pois trata ao mesmo tempo da exceção na institucionalidade e da institucionalidade na exceção, são apontadas na análise de Porto Macedo Jr.: "Para Schmitt é difícil prever e definir com clareza quais são os limites do estado de exceção. É certo que uma Constituição pode até mesmo prever a competência do governante durante o período de exceção. Todavia, não pode determinar com toda precisão o limite deste poder soberano. O soberano decide tanto sobre a ordem que subsiste no caso extremo de emergência, quanto sobre as ações que devem ser realizadas para superar o caos, trazendo de volta a normalidade. Ele está fora do ordenamento jurídico normalmente vigente e, entretanto, pertence a este, pois, que cabe a ele a competência para decidir se a Constituição in toto pode ser suspensa" (p. 137).

Todas estas polêmicas schmittianas sobre exceção e normalidade, ainda, se somarão às da própria trajetória pessoal de Schmitt, objeto 
de análise na parte inicial da obra de Porto Macedo Jr., de tal sorte que o epíteto de "jurista do nazismo" se revelará ainda muito pouco para encerrar em si todas os polêmicos debates sobre Schmitt.

\section{PACHUKANIS: CAPITALISMO E DIREITO}

A análise de Pachukanis e sua trajetória de teórico marxista do direito é o fio condutor da obra de Márcio Bilharinho Naves, Marxismo e direito - um estudo sobre Pachukanis, originalmente tese de doutorado apresentada na Unicamp. $\mathrm{O}$ autor resgata conceitos em geral negligenciados não só pelo jurista - que de modo geral os desconhece - mas também pelo próprio marxista, que são os conceitos de Marx sobre a relação entre direito e capitalismo, que imediatamente pode se desdobrar para a relação entre as instituições e o capital, e também para o Estado e a democracia.

$\mathrm{Na}$ concepção comum e vulgar do marxismo, muito pouco resta de interesse para com o direito. Nem o próprio Marx dedicou ao problema jurídico muitas linhas nem os marxistas dedicaram-lhe obras relevantes. Talvez as primeiras preocupações neste sentido somente tenham surgido quando as revoluções socialistas de inspiração marxista foram obrigadas, pelas necessidades práticas, a se indagar sobre o que fazer com o direito e, ainda, que novo direito empreender, se é que deveriam empreender algum.

Pachukanis está na linha de frente deste pensamento. Na época da Revolução Soviética, participou, como personagem principal, de todas essas polêmicas de seu tempo. A voga da época, segundo aponta Naves, era a de considerar o direito uma ideologia a serviço do capital, e, se a serviço estivesse do capital, bastaria apenas inverter seu senhorio para que se invertesse seu serviçal. Outros, até mesmo de inspiração marxista, tratavam do direito como problema de psicologismo, pretendendo com isso alguma ciência. Pachukanis, de todos os juristas soviéticos, é quem fará o retorno mais acurado à obra de Marx, buscando desvendar, na economia política, as relações entre direito, política e capital.

Naves resgata o problema metodológico de Pachukanis, demonstrando claramente que, tal como Marx, o jurista soviético utiliza-se dos mesmos instrumentais de análise do capital, fazendo da compreensão das formas históricas mais avançadas a chave para o entendimento das relações sociais. Diz o autor: "Podemos dizer que a concepção de Pachukanis corresponde inteiramente às reflexões que Marx desenvolve, sobretudo nos Grundrisse e em $O$ Capital, a propósito do lugar central que 
ocupa a análise da forma para compreender as relações sociais capitalistas. Distinguindo-se dos economistas burgueses que 'vêem como se produz no interior da relação capitalista', mas são incapazes de perceber como essa relação é produzida, e nem como são produzidas nela as condições de sua superação, 'o que suprime a sua justificação histórica como forma necessária do desenvolvimento econômico, da produção da riqueza material', Marx funda a distinção entre a concepção materialista da história e a concepção burguesa da história em uma teoria das formas ou dos modos de produção" (p. 48).

O grande elemento diferencial de Pachukanis, ou seja, a sua metodologia de análise do direito tal qual a análise de Marx do capital, leva a conclusões bastante diversas daquelas tradicionais dos juristas soviéticos, que no máximo obtinham inspiração nas obras primeiras e políticas de Marx, mas nunca em suas obras de economia política. O problema da ligação do capitalismo à circulação mercantil passa a assumir, em Pachukanis, dimensões de vulto.

Diz Naves: "Relacionar a forma da mercadoria com a forma jurídica resume, para Pachukanis, o essencial de seu esforço teórico" (p. 53). Será a forma mercadoria que constituirá o direito, e a igualdade formal do mercado - comprador e vendedor tomados como equiparados, e considerados sempre pela liberdade de contratar (autonomia da vontade) passa a ser, então, a igualdade formal do direito, e nisto se encerra a célebre constatação de Marx, em $O$ Capital, do comércio como o paraíso dos direitos humanos. Esta compreensão da forma jurídica como forma da mercadoria leva a problemas, apontados por Naves, como o das críticas empreendidas a Pachukanis pelo olvidamento da produção e do trabalho em sua análise do direito, baseado que estaria em uma perspectiva essencialmente da circulação mercantil. A mais polêmica das reflexões de Pachukanis, no entanto, são as que dizem respeito ao Estado e à revolução, ou seja, à legalidade revolucionária.

Rompendo com autores como Stutchka, que defendiam a existência de uma legalidade revolucionária - e portanto serviriam de apoio para a instauração de um Estado soviético - Pachukanis insiste no caráter provisório da legalidade revolucionária, e denuncia a existência do Estado socialista como manutenção da circulação mercantil e das trocas capitalistas. A extinção da forma jurídica passa a ser, para Pachukanis, o distintivo da revolução socialista que almeja o fim do capitalismo. Por estas posições, Pachukanis foi gradativamente colocado à margem do processo de consolidação do regime soviético, até sofrer dos expurgos stalinistas, quando foi 
obrigado a um longo e traumático processo de revisão de seus conceitos teóricos sobre o direito e a política.

No entendimento conclusivo de Naves, "a concepção mesma do 'socialismo' stalinista - na verdade, um capitalismo de Estado - exigia a elaboração de uma doutrina do direito que lhe servisse de fundamento ideológico. Começamos a perceber também as razões que levaram à completa renúncia dos postulados teóricos originais de Pachukanis, a necessidade imperiosa de apagar da memória comunista os vestígios da irredutibilidade burguesa de todo o direito, apagar suas palavras que denunciavam a contradição inerente a um projeto de socialismo fundado na ilusão jurídica” (p. 167).

\section{A POLÍTICA E O CAPITAL PARA ALÉM DO DIREITO}

Os mais antípodas dos pensadores do direito do século XX Pachukanis e Schmitt -, compartilhando de várias críticas exacerbadas ao institucionalismo liberal - ao modelo kelseniano - igualam-se, um no veio conservador e outro no revolucionário, ao papel dado à política, à exceção, para além do direito e da normatividade. Num mundo em que a estabilidade das leis nada parece ser em face do capitalismo multinacional, do imperialismo e de homens da exceção como George W. Bush, talvez os extremos necessitem ser revisitados, pois parece que é ainda por eles que compreenderemos muito do direito e da política de nossos tempos.

ALYSSON LEANDRO MASCARO é advogado, doutor em Filosofia do Direito pela USP e membro do Conselho Pedagógico da Escola de Governo. 


\section{RESUMOS/ABSTRACTS}

\section{NOS EXTREMOS DO DIREITO: NOVAS \\ OBRAS SOBRE SCHMITT E PACHUKANIS}

Dois livros que tratam de figuras situadas em pontos extremos do pensamento jurídico no século XX (Carl Schmitt e a fundamentação do direito, de Ronaldo Porto Macedo Jr. e Marxismo e direito - um estudo sobre Pachukanis, de Márcio Bilharinho Naves) são examinados.

Palavras-chave: Schmitt; Pachukanis; marxismo; nazismo.

\section{AT THE EXTREMES OF RIGHT}

Two books about authors representing extreme positions of the juridical thought in the XXth century (Carl Schmitt e a fundamentação do direito, by Ronaldo Porto Macedo Jr., and Marxismo e direito - um estudo sobre Pachukanis, by Márcio Bilharinho Naves) are examined.

Keywords: Schmitt; Pachukanis; Marxism; Nazism. 